\title{
Disassociation of Postischemic Recovery of Renal Adenosine Triphosphate and Cellular Integrity ${ }^{1}$
}

\author{
IVY I. BOYDSTUN, GUNILLA THULIN, XIAO-HONG ZHU, MALCOLM J. AVISON, \\ KAREN M. GAUDIO, AND NORMAN J. SIEGEL
}

The Department of Pediatrics and Molecular Biophysics and Biochemistry, Yale University School of Medicine,

New Haven, Connecticut 06510

\begin{abstract}
Previous studies from our laboratory have demonstrated that postischemic infusion of thyroxin $\left(T_{4}\right)$ will augment the restoration of cellular ATP and enhance the recovery of renal function. It has not been clear, however, whether $\mathrm{T}_{4}$ has a direct effect on mitochondrial ATP synthesis or an indirect effect by stabilization of the plasma membrane. To differentiate these putative effects, rats were subjected to $45 \mathrm{~min}$ of renal ischemia and given either normal saline $(0.5 \mathrm{~mL})$ or $\mathrm{T}_{4}(20 \mu \mathrm{g} / 100 \mathrm{~g}$ body weight $)$ during the first $15 \mathrm{~min}$ of reflow. Cellular ATP levels were assessed by ${ }^{31} \mathrm{P}$-nuclear magnetic resonance spectroscopy, and release of lactate dehydrogenase (LDH) was used as an index of plasma membrane integrity at 30 and $120 \mathrm{~min}$ of reflow. In rats given normal saline, renal ATP had returned to only $57.9 \pm 1.4 \%$ of preischemic values at 30 min of reflow and $66.1 \pm 1.4 \%$ by $120 \mathrm{~min}$. LDH release was $13 \pm 0.89 \%$ at $30 \mathrm{~min}$ and $14.6 \pm 1.6 \%$ at $120 \mathrm{~min}$. In contrast, $\mathrm{T}_{4}$-treated animals had ATP levels of $70.2 \pm$ $2.0 \%$ at $30 \mathrm{~min}$ and $84.0 \pm 1.9 \%$ at $120 \mathrm{~min}$, whereas $\mathrm{LDH}$ release was elevated to values similar to those in normal saline-treated rats, $14.9 \pm 1.5 \%$ and $14.4 \pm 0.5 \%$ at 30 $\mathrm{min}$ and $120 \mathrm{~min}$, respectively (nonischemic LDH $8.8 \pm$ $0.8 \%$ ). These data suggest that $T_{4}$ stimulates the recovery of renal ATP by a direct effect on synthesis rather than an indirect effect related to global improvement in cellular integrity. (Pediatr Res 33: 595-597, 1993)
\end{abstract}

Abbreviations

$\mathrm{T}_{4}$, thyroxin

NS, normal saline

NMR, nuclear magnetic resonance

LDH, lactate dehydrogenase

BW, body weight

It has been well established that treatment with $T_{4}$ has a beneficial effect in accelerating recovery after toxic $(1,2)$ and ischemic acute renal failure (3) in animals. The enhanced recovery of renal function has been demonstrated to parallel the augmented restoration of cellular ATP in animals treated with $\mathrm{T}_{4}$ after the renal injury. Whether $\mathrm{T}_{4}$ affects mitochondrial ATP synthesis directly or works by an indirect mechanism, such as restitution of cellular integrity, has not been established. The

Received October 27, 1992; accepted January 26, 1993

Correspondence: Ivy I. Boydstun, M.D., Yale University School of Medicine, Department of Pediatrics, 333 Cedar St., New Haven, CT 06510.

Supported in part by NIH Training Grant DK07276, NIDDK 44336, and the Baxter Extramural Grant Program. Dr. Boydstun is a postdoctoral fellow of the National Kidney Foundation.

${ }^{1}$ Portions of this work were presented at the May 1992 joint meeting of the American Pediatric Society and the Society for Pediatric Research. purpose of the present study was to determine whether the beneficial effect of postischemic treatment with $T_{4}$ involves stabilization of the injured plasma membrane of renal proximal tubule cells.

\section{MATERIALS AND METHODS}

Male Sprague-Dawley rats weighing 200 to $290 \mathrm{~g}$ were anesthetized with thiobutabarbital (Inactin, Byk Gulden, Konstanz, Germany) $80 \mathrm{mg} / \mathrm{kg}$ by intraperitoneal injection and placed on a heated animal board to maintain body temperature between 36 and $37^{\circ} \mathrm{C}$. A tracheostomy was performed, and an external jugular vein catheter (PE-50) was placed. Isotonic saline was administered to replace surgical fluid losses $(2 \% \mathrm{BW})$ and provide maintenance fluid at $1.2 \mathrm{~mL} / \mathrm{h}$. The abdominal aorta and right renal artery were isolated through a midline abdominal incision. Ten min before ischemia, $500 \mathrm{U} / \mathrm{kg}$ heparin were infused. A vascular clamp was placed proximal to the origin of the left renal artery, and a Silastic sling was placed around the right renal artery to induce $45 \mathrm{~min}$ of bilateral renal ischemia. After the ischemic period, the kidneys were allowed either $30 \mathrm{~min}$ or 120 min of reperfusion. Rats received either NS $(0.5 \mathrm{~mL})$ or $\mathrm{T}_{4}(20$ $\mu \mathrm{g} / 100 \mathrm{~g} \mathrm{BW})$ during the immediate reflow period. Nonischemic control animals were anesthetized, sham-operated, and studied in the same manner as ischemic animals.

Tubule harvest. At the end of the reperfusion interval, an aortic catheter (PE-90) was placed distal to the origin of the renal arteries to perfuse the kidneys in situ with $90 \mathrm{mg}$ of collagenase (Boehringer Mannheim, Indianapolis, IN) dissolved in $60 \mathrm{~mL}$ buffered solution over $20 \mathrm{~min}$. After flushing with ice-cold buffer solution, the kidneys were rapidly excised and placed on ice, and capsules were removed. The cortex was gently scraped and suspended in a balanced buffered solution containing metabolic substrates (4), then stirred on ice. The suspension was filtered through a fiber mesh (Tetko, Depew, NY) to produce a suspension enriched in proximal tubules, which was then washed and sedimented by gentle centrifugation at $4^{\circ} \mathrm{C}$. Microscopic inspection of the preparation was performed to ensure minimal contamination with glomeruli. Throughout the harvest procedure, the tubules were equilibrated with $95 \% \mathrm{O}_{2} / 5 \% \mathrm{CO}_{2}$ and kept on ice. Previous studies (5) have extensively validated this method of harvesting injured proximal tubule segments for in vitro evaluation after an in vivo ischemic insult. Such tubule segments recapitulate the metabolic and histomorphologic characteristics of ischemia.

$L D H$ assay. The tubule suspension was warmed to $37^{\circ} \mathrm{C}$ and bubbled with $95 \% \mathrm{O}_{2} / 5 \% \mathrm{CO}_{2}$ in a shaker bath for $10 \mathrm{~min}$, then centrifuged to produce a supernatant sample and a cellular-plussupernatant sample. $\mathrm{LDH}$ was assayed immediately on each sample spectrophotometrically by following the disappearance of NADH at $340-\mathrm{nm}$ wavelength as described by Bergmeyer et al. (6). $\mathrm{LDH}$ was expressed as a percentage of $\mathrm{LDH}$ released into 
the supernatant compared with LDH in the sonicated cellularplus-supernatant sample.

ATP determination. Animals were prepared as previously described in Materials and Methods. Each animal's body temperature was maintained at 36 to $37^{\circ} \mathrm{C}$ with a recirculating water bed. After exposure of the renal arteries through a midline abdominal incision, rats received heparin $500 \mathrm{mg} / \mathrm{kg} \mathrm{BW}$ via the jugular catheter. A balloon cuff vascular occluder (In Vivo Metric, Healdsburg, CA) was looped around the aorta, distal to the origin of the celiac artery but proximal to the origin of both renal arteries. A femoral artery catheter was placed to continuously monitor arterial pressure distal to the site of the vascular cuff to assure complete occlusion of the aorta during the ischemic period.

The left kidney was exposed by a flank incision and placed in a saddle-shaped NMR coil that fit snugly around the organ. ${ }^{31} \mathrm{P}$ NMR spectra were obtained with the Bruker Biospec I $4.7 \mathrm{~T}$ spectrometer (Bruker Instruments, Inc., Billerica, MA), operating at $81 \mathrm{MHz}$. Each spectrum consisted of 128 acquisitions, using a $90^{\circ}$ pulse 2 -s relaxation delay to ensure that the $\beta$-ATP resonance $\left(T_{1}=400 \mathrm{~ms}\right)$ was fully relaxed. Improvements in the radiofrequency transceiver coil and spectrometer have led to enhanced ${ }^{31} \mathrm{P}$ sensitivity, allowing us to acquire ${ }^{31} \mathrm{P}$ spectra with 3.5 -min time resolution. Four control spectra were taken to ensure stability of the preparation and establish the preischemic ATP level. Both kidneys were then made ischemic for $45 \mathrm{~min}$ by inflating the balloon cuff of the vascular occluder. During this time, the femoral artery pressure was $0 \mathrm{~mm} \mathrm{Hg}$ and constant. After $45 \mathrm{~min}$ of ischemia, the cuff was deflated, and the animals received either $0.5 \mathrm{~mL} \mathrm{NS}$ or $20 \mu \mathrm{g} / 100 \mathrm{~g} \mathrm{BW} \mathrm{T}_{4}$ during the first 5 to $7 \mathrm{~min}$ of reflow. There were no changes in coil loading or position during any of these maneuvers; therefore, reshimming was not required. Spectra were collected before, during, and for $120 \mathrm{~min}$ after the insult. Thus, each animal served as its own control. In control animals, the $\beta$-ATP peak was stable and varied by $0.33 \%$ of the preischemic ATP value over the $120 \mathrm{~min}$ of the study.

Spectra were processed using a convolution difference to remove the broad phospholipid resonance and a mild Lorentzian filter $(20 \mathrm{~Hz})$. Renal ATP levels were assessed by comparing changes in the area of the $\beta$-phosphate peak at each time interval with the preischemic values. Areas were determined using standard NMR software (Bruker).

Statistical methods. Results are presented as mean values \pm SEM. Comparisons between groups were done by $t$ test, with differences considered significant when the $p$ value was $<0.05$.

\section{RESULTS}

Cell membrane integrity (Fig. I). The effect of postischemic $\mathrm{T}_{4}$ treatment on cell membrane integrity, as assessed by the percentage of LDH released from injured cells, can be evaluated by comparing NS-treated animals with those receiving $\mathrm{T}_{4}$. Nonischemic controls had a mean LDH release of $8.8 \pm 0.8 \%(n=$ 4 animals). At $30 \mathrm{~min}$ of postischemic reflow, NS-treated subjects had an $\mathrm{LDH}$ release of $13 \pm 0.8 \%$ ( $n=5$ animals), and $\mathrm{T}_{4}$ treatment resulted in a mean of $14.9 \pm 1.5 \%(n=4$ animals $)$. By 120 min of reperfusion, similar results were obtained. LDH release was $14.6 \pm 1.6 \%$ ( $n=5$ animals) in the NS-treated group and $14.4 \pm 0.5 \%$ ( $n=5$ animals) in the $T_{4}$-treated group. Although ischemic injury caused a significant increase in LDH release compared with controls $(p<0.05)$, no statistically significant difference was detected in plasma membrane integrity between NS- and $\mathrm{T}_{4}$-treated groups at either time interval.

Cellular ATP recovery (Fig. 2). In all animals, renal ATP levels evaluated by ${ }^{31}$ P-NMR spectroscopy fell to below $20 \%$ of control levels within $10 \mathrm{~min}$ of aortic occlusion and remained at that level during the remainder of the ischemic insult. ATP levels returned to only $57.9 \pm 1.4 \%$ of nonischemic control values by $30 \mathrm{~min}$ of reflow in NS-treated animals ( $n=8$ animals). In

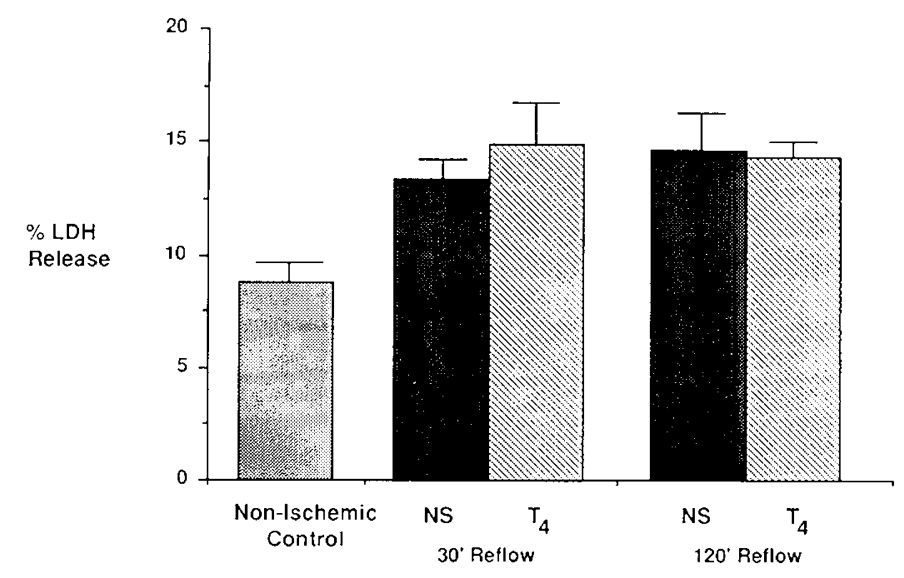

Fig. 1. Effect of $T_{4}$ on cell membrane integrity comparison of NSand $\mathrm{T}_{4}$-treated animals. Increase in $\mathrm{LDH}$ release was statistically significant $(p<0.05)$ for all groups with 45 min of renal ischemia compared with nonischemic controls. $\mathrm{LDH}$ released from injured cells was not significantly different between NS and $\mathrm{T}_{4}$ groups at either $30 \mathrm{~min}$ or 120 min of reflow.

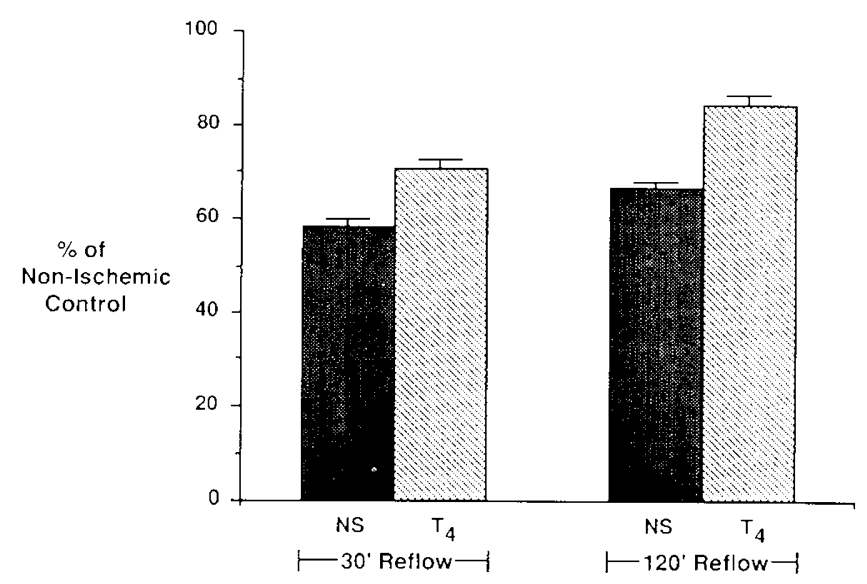

Fig. 2. ATP recovery by ${ }^{31} \mathrm{P}-\mathrm{NMR}$ spectroscopy. NS- and $\mathrm{T}_{4}$-treated ischemic animals compared at 30 and $120 \mathrm{~min}$ of reflow after $45 \mathrm{~min}$ of renal ischemia. A statistically significant $(p<0.05)$ improvement was seen in $\mathrm{T}_{4}$-treated animals at both time intervals.

contrast, administration of $\mathrm{T}_{4}$ improved levels to $70.2 \pm 2.0 \%$ at 30 min of reflow ( $n=11$ animals). By $120 \mathrm{~min}$ of reperfusion, the ATP levels increased to $66.1 \pm 1.4 \%$ and $84.0 \pm 1.9 \%$ in the $\mathrm{NS}$ and $\mathrm{T}_{4}$ groups, respectively. At both time points, the difference between the experimental groups was statistically significant.

\section{DISCUSSION}

Although the beneficial effects of $\mathrm{T}_{4}$ in enhancing recovery after acute renal injury have been well established (1-3), the mechanisms of $T_{4}$ action have not been elucidated. Recovery of injured tissue requires the reestablishment of cellular ATP levels to provide energy for repair of the cell, ongoing metabolic requirements, and support of the regenerative and proliferative process $(1,7-10)$. In fact, it has been shown that increases in glomerular filtration rate, filtered load, and tubular transport that are not accompanied by concomitant increases in cellular energy are associated with increased swelling and necrosis of injured renal tubule epithelium $(8,9)$. Moreover, cellular nucleotides have been shown to stimulate cell growth and repair (7, 10). Cellular energy is also required for regenerative processes such as heat-shock protein induction and function $(11,12)$. Therefore, the mechanism by which $\mathrm{T}_{4}$ augments recovery of cellular ATP has been of interest. 
One proposed mechanism for the salutary effect of $\mathrm{T}_{4}$ has been through an indirect stabilization of injured cells, thereby preventing the transcellular leakage of adenine nucleotides and precursors required for ATP resynthesis. Phospholipids play an important role in regulation and maintenance of cellular membranes and have been demonstrated to be significantly altered by renal ischemia (13). Ballard et al. (14) have shown that thyroid hormone stimulates the incorporation of phospholipids into developing rat and rabbit lung tissue. This study was designed to test the hypothesis that improvements in renal cell integrity would precede improvements in cellular energy levels.

LDH release by injured cells is a reliable indicator of plasma membrane integrity and has been used to evaluate many forms of tissue injury $(4,5,15,16)$. Takano et al. (17) found that release of $\mathrm{LDH}$ occurred progressively with increasing duration of anoxia in rabbit proximal tubules, reflecting an increase in the degree of cellular damage with prolonged anoxia. Doctor and Mandel (18) demonstrated a similar progressive increase in LDH release in rat tubules when anoxic intervals were extended to 60 min, suggesting that $\mathrm{LDH}$ release can be used as an index of the severity of the cellular injury. In the present study, a fixed period of in vivo renal ischemia was followed by reperfusion for 30 or $120 \mathrm{~min}$. Postischemic treatment with $\mathrm{T}_{4}$ did not significantly improve LDH release in proximal tubule cells at either reflow interval as compared with NS-treated control animals. These results indicate that postischemic administration of $\mathrm{T}_{4}$ does not directly alter cellular integrity during the early reflow period.

To accurately determine cellular ATP levels in vivo, so that we could obtain the data necessary to test our hypothesis, we had to modify our previous techniques for the determination of ATP by ${ }^{31} \mathrm{P}-\mathrm{NMR}$ spectroscopy. These technical improvements included a redesigned and rebuilt coil, use of a cuffed vascular occluder that did not change the load factor or position of the kidney during ischemia, and placement of a femoral artery line to be sure the vascular occlusion was complete and was effectively released. These improvements in NMR technique have now: 1 ) allowed acquisition of spectra at intervals of $3.5 \mathrm{~min}$ instead of $7 \mathrm{~min}$, as previously reported $(19) ; 2$ ) obviated the need for reshimming, inasmuch as the kidney does not move during occlusion or reperfusion; and 3) enhanced sensitivity with improved signal-to-noise ratio. Changes in cellular ATP during the early rapid phase of recovery, the first $30 \mathrm{~min}$ of reflow, can now be examined.

In the present study, ATP levels for $\mathrm{T}_{4}$-treated animals were significantly higher at both $30 \mathrm{~min}$ and $120 \mathrm{~min}$ of reflow. Although we have previously reported the augmented recovery of cellular ATP at $120 \mathrm{~min}$, the present study not only reconfirms these observations (19) but provides new data that postischemic ATP levels are increased very rapidly after the administration of $\mathrm{T}_{4}$, i.e. within $30 \mathrm{~min}$. The impact of this improvement in cellular ATP during early reflow and on the long-term recovery from ischemic acute renal failure has been delineated. Our laboratory has shown previously that improvement in cellular energetics is associated with enhanced renal function, amelioration of histomorphologic damage, and sustained recovery of glomerular and tubule function $(3,9,19)$.

In conclusion, the present study has documented two new findings: 1) postischemic recovery of cellular ATP is enhanced significantly by $\mathrm{T}_{4}$ treatment as early as $30 \mathrm{~min}$ of reflow, but 2) this augmentation of renal ATP levels is not preceded or accompanied by a concomitant improvement in cellular integrity. These results would suggest that ATP synthesis may be directly affected by $\mathrm{T}_{4}$, by mechanisms such as stimulation of inorganic phosphate transport, or possibly by augmenting ADP translocator activity in mitochondria. In fact, mitochondrial nucleotide transporter activity has been shown to be reduced after ischemia $(20,21)$, and this transporter is known to be sensitive to thyroid hormones (22). Further investigation is required to explore these possibilities and to understand the complex interactions of the diverse cellular events that occur during recovery from ischemic acute renal failure.

Acknowledgment. The authors thank Marie Campbell for her exceptional secretarial assistance.

\section{REFERENCES}

1. Michael UF, Logan SL, Meeks LA 1991 The beneficial effects of thyroxine on nephrotoxic acute renal failure in the rat. J Am Soc Nephrol 1:1236-1240

2. Siegel NJ, Gaudio KM, Katz LA, Reilly HF, Ardito TA, Hendler FG, Kashgarian M 1984 Beneficial effect of thyroxin on recovery from toxic acute renal failure. Kidney Int 25:906-911

3. Sutter PM, Thulin G, Stromski M, Ardito T, Gaudio KM, Kashgarian M, Siegel NJ 1988 Beneficial effect of thyroxin in the treatment of ischemic acute renal failure. Pediatr Nephrol 2:1-7

4. Gaudio KM, Thulin G, Ardito T, Kashgarian M, Siegel NJ 1991 Redistribution of cellular energy following renal ischemia. Pediatr Nephrol 5:591-596

5. Gaudio KM, Thulin G, Ardito T, Kashgarian M, Siegel NJ 1989 Metabolic alterations in proximal tubule suspensions obtained from ischemic kidneys. Am J Physiol 257:F383-F389

6. Bergmeyer HU, Bernt E, Hess B 1963 Lactate dehydrogenase. In: Bergmeyer HU (ed) Methods of Enzymatic Analysis. Academic Press, New York, pp 736-743

7. Humes HD, Creslinski DA, Johnson LB, Sanchez IO 1992 Triiodothyronine enhances renal tubule cell replication by stimulating EGF receptor gene expression. Am J Physiol 262:F540-F545

8. Brezis M, Rosen S, Silva P, Epstein F 1984 Editorial review. Renal ischemia: a new perspective. Kidney Int 26:375-383

9. Gaudio KM, Stromski M, Thulin G, Ardito T, Kashgarian M, Siegel NJ 1986 Postischemic hemodynamics and recovery of renal adenosine triphosphate. Am J Physiol 251:F603-F609

10. Toback FG 1992 Regeneration after acute tubular necrosis. Kidney Int 41:226246

11. Pelham H 1988 Heat-shock proteins: coming in from the cold. Nature (Lond) 332:776-777

12. Pelham HRB 1986 Speculations on the functions of the major heat shock and glucose-related proteins. Cell 46:959-961

13. Matthys E, Patel Y, Kreisberg S, Stewart JH, Venkatachalam MA 1984 Lipid alterations induced by renal ischemia: pathogenic factor in membrane damage. Kidney Int 26:153-161

14. Ballard PL, Hovey ML, Gonzales LK 1984 Thyroid hormone stimulation of phosphatidyl-choline synthesis in cultured fetal rabbit lung. J Clin Invest 74:898-905

15. Andreoli SP, Baehner RL, Bergstein JM 1985 In vitro detection of endothelial cell damage using 2-deoxy-D- ${ }^{3} \mathrm{H}$-glucose: comparison with chromium 51 , ${ }^{3} \mathrm{H}$-leucine, ${ }^{3} \mathrm{H}$-adenine, and lactate dehydrogenase. J Lab Clin Med 106:253261

16. Lash LH, Woods EB 1991 Cytotoxicity of alkylating agents in isolated rat kidney proximal tubular and distal tubular cells. Arch Biochem Biophys 286:46-56

17. Takano T, Soltoff SP, Murdaugh S, Mandel LJ 1985 Intracellular respiratory dysfunction and cell injury in short-term anoxia of rabbit renal proximal tubules. J Clin Invest 76:2377-2384

18. Doctor RB, Mandel LJ 1991 Minimal role of xanthine oxidase and oxygen free radicals in rat renal tubular reoxygenation injury. $\mathrm{J}$ Am Soc Nephrol 1:959-969

19. Stromski ME, Cooper K, Thulin G, Gaudio KM, Siegel NJ, Shulman RG 1986 Chemical and functional correlates of postischemic renal ATP levels. Proc Natl Acad Sci USA 83:6142-6145

20. Henke W, Kotzek S, Nicel E, Dippe M, Jung K 1990 Ischemia-induced alterations of rat kidney mitochondria. Transplant 49:997-999

21. Henke W, Jung K 1991 Ischemia decreases the content of the adenine nucleotide translocator in mitochondria of rat kidney. Biochem Biophys Acta 1056:71-75

22. Babior BM, Creagan S, Ingbar SH, Kipnes RS 1973 Stimulation of mitochondrial adenosine diphosphate uptake by thyroid hormones. Proc Natl Acad Sci USA 70:98-102 